\title{
Molecular Characterization and Distribution of Two Strains of Dasheen mosaic virus on Taro in Hawaii
}

Yanan Wang, College of Plant Protection, Agricultural University of Hebei, Baoding, 071001, P. R. China; and College of Tropical Agriculture and Human Resources, University of Hawaii, Honolulu, HI 96822; Beilei Wu, Institute of Plant Protection, Chinese Academy of Agricultural Sciences, Beijing 100193, P. R. China; and Wayne B. Borth, Islam Hamim, James C. Green, Michael J. Melzer, ${ }^{\dagger}$ and John S. Hu, College of Tropical Agriculture and Human Resources, University of Hawaii, Honolulu, HI 96822

\begin{abstract}
Dasheen mosaic virus (DsMV) is one of the major viruses affecting taro (Colocasia esculenta) production worldwide. Whole genome sequences were determined for two DsMV strains, Hawaii Strain I (KY242358) and Hawaii Strain II (KY242359), from taro in Hawaii. They represent the first full-length coding sequences of DsMV reported from the United States. Hawaii Strains I and II were 77 and $85 \%$ identical, respectively, with other completely sequenced DsMV isolates. Hawaii Strain I was most closely related to vanilla mosaic virus (VanMV) (KX505964.1), a strain of DsMV infecting vanilla in the southern Pacific Islands. Hawaii Strain II was most closely related to a taro DsMV isolate CTCRI-II-14 (KT026108.1) from India. Phylogenetic analysis of all available DsMV

isolates based on amino acid sequences of their coat protein showed some correlation between host plant and genetic diversity. Analyses of DsMV genome sequences detected three recombinants from China and India among the six isolates with known complete genome sequences. The DsMV strain NC003537.1 from China is a recombinant of KJ786965.1 from India and Hawaii Strain II. Another DsMV strain KT026108.1 is a recombinant of Hawaii Strain II and NC003537.1 from China. The third DsMV strain KJ786965.1 from India is a recombinant of Hawaii Strain II and NC003537.1 from China. To our knowledge, this is the first report of recombination events in DsMV. Both Hawaii Strains I and II of DsMV were found widespread throughout the Hawaiian islands.
\end{abstract}

Taro (Colocasia esculenta L. [Schott]) is in the family Araceae. Its origins are in India and adjacent areas of Southeast Asia (Ram et al. 2003), where it is an important staple food crop with great economic importance. Vegetative propagation makes taro especially susceptible to viruses and other pathogens that are easily transmitted in propagation material (Babu et al. 2011). Dasheen mosaic virus (DsMV), first reported in 1970 (Zettler et al. 1970), is one of the major viruses infecting taro. Typical symptoms are a feather-like mosaic and distortion of leaves, but these symptoms are affected by host cultivar and season (Revill et al. 2005). DsMV is spread by vegetative propagation (Babu et al. 2011) and by aphids (Reyes et al. 2006), the former causing potentially important decreases in taro production through the movement of infected germplasm. DsMV belongs to the genus Potyvirus in the family Potyviridae. It has flexuous, filamentous particles $750 \mathrm{~nm}$ long.

Partial genome sequences of DsMV have been reported from different hosts in many countries (Chen et al. 2001; Pappu et al. 1994a, b; Reyes Castro et al. 2005). Examples of partial genomes include: the 3'-terminal region and coat protein of DsMV infecting Caladium hortulanum ( $\mathrm{Li}$ et al. 1994, 1998), the core region of the CP from DsMV infecting Colocasia esculenta (Babu et al. 2011), the CP region of the DsMV isolate YX infecting Nelumbo nucifera (Yu et al. 2015), DsMV-VN/Ce2 polyprotein and the DsMV CP from C. esculenta and Typhonium trilobatum, respectively, in Vietnam (Ha et al. 2008), and part of the NIb gene, the entire CP gene, and the 3'-untranslated region of DsMV infecting Pinellia ternata (Shi et al. 2005) and Caladium hortulanum, respectively (Li et al. 1998). Four complete genome sequences have been reported: an isolate of DsMV infecting Zantedeschia aethiopica in China (Chen et al. 2001), the CTCRI-II-14 isolate infecting C. esculenta (Liebrecht and Winter, unpublished data), the T10 isolate infecting Amorphophallus paeoniifolius in India (Kamala et al.,

${ }^{\dagger}$ Corresponding author: Michael J. Melzer; E-mail: melzer@hawaii.edu

*The $\boldsymbol{e}$-Xtra logo stands for "electronic extra" and indicates that one supplementary table is published online.

Accepted for publication 5 August 2017.

() 2017 The American Phytopathological Society unpublished data), and vanilla mosaic virus (VanMV) isolated from Vanilla tahitensis in the Cook Islands (Puli'uvea et al. 2016). The DsMV genome consists of a positive-sense, single-stranded RNA containing a $5^{\prime}$-untranslated region ( $5^{\prime}$-UTR), a single major open reading frame (ORF) encoding a large polyprotein, and a $3^{\prime}$-UTR region terminating in a poly-A tail. The large polyprotein is cleaved into 10 proteins; from $5^{\prime}$ to $3^{\prime}$ they are: P1 HC-Pro, P3, 6K1, CI, 6K2, VPg, NIa-Pro, NIb, and the coat protein (CP) (Kamala et al. 2015).

In this study, we determined the full-length coding sequences of two strains of DsMV infecting taro in Hawaii. This is the first report of the genome sequence of DsMV from the United States. Hu et al. (1995) used ELISA to survey 14 commercial taro fields on the islands of Hawaii, Molokai, and Oahu, and identified DsMV in many samples. Since then, more sensitive plant virus detection procedures have been developed, including PCR-based methods (Babu et al. 2011; Lima and Nascimento 2015). We used RT-PCR to analyze the molecular variation and recombination among the Hawaii strains of DsMV and to determine their geographical distribution in Hawaii.

\section{Materials and Methods}

Sample collection. Taro leaf samples "Taro Sample I" and "Taro Sample II" with severe dasheen mosaic symptoms (Fig. 1) were collected in March and May of 2016, respectively, from the Waimanalo Research Station $\left(21^{\circ} 20^{\prime} 13.9^{\prime \prime} \mathrm{N}, 157^{\circ} 42^{\prime} 50.6^{\prime \prime} \mathrm{W}\right)$ on the island of Oahu, Hawaii. Nucleic acids isolated from these samples were used to determine the genomic sequences of DsMV strains in Hawaii. To survey for the occurrence of DsMV in Hawaii, 328 symptomatic and asymptomatic whole-leaf samples were collected randomly from the five main islands of Oahu, Hawaii, Maui, Molokai, and Kauai, and analyzed by PCR.

Double-stranded RNA extraction and cDNA library construction. Double-stranded RNAs (dsRNAs) were isolated from $10 \mathrm{~g}$ of leaf tissue for each of the Taro Sample I and Taro Sample II using the protocol of Morris and Dodds (1979) with minor modifications. After extraction, the pellets were washed with $70 \%$ ethanol and then precipitated with sodium acetate (3 M, pH 5.2) and isopropanol. The pellets were washed again with $70 \%$ ethanol, dried, and resuspended in $500 \mu \mathrm{l}$ of nanopure $\mathrm{H}_{2} \mathrm{O}$ and the nucleic acids were then concentrated on YM50 columns (Millipore, Bedford, MA). Five-microliter aliquots of dsRNA were analyzed by electrophoresis in a $1 \%(\mathrm{w} / \mathrm{v})$ agarose gel in TAE buffer. Double-stranded cDNA libraries were constructed for 
each sample according to the protocol described by Zhang et al. (2016) except that SuperScript III reverse transcription (Invitrogen, Carlsbad, CA) was used to generate cDNAs.

Next generation sequencing. After purification, the cDNA libraries underwent next generation sequencing (NGS) using an Illumina MiSeq platform, producing $2 \times 300$ bp (V3) 44-50 M paired-end reads at SeqMatic LLC (Fremont, CA). Low-quality sequence short reads (<30 nt) and primer sequences were trimmed. VirFind (http:// virfind.org) was used to analyze the NGS data. De novo assemblies were then conducted on the trimmed raw sequence reads for each sample using Geneious Pro 7.1.5 (Biomatters Ltd., Auckland, New Zealand). In addition, the NGS reads for each sample were separately mapped to a DsMV reference genome (GenBank accession no. KT026108).

Sanger sequencing. We used conventional Sanger dideoxy sequencing to verify sequence gaps or low-coverage regions in the DsMV genomes generated from the NGS data. Primers based on the NGS data were designed to amplify these regions of low coverage or missing sequences (Supplementary Table S1).

To determine the 3'-terminal sequences of the genomes, cDNAs were generated from dsRNA using an oligo-dT primer 'No. 900 R' and MMLV reverse transcription (Promega, Madison, WI), according to the manufacturer's instructions. The oligo-dT primer was also used for subsequent PCR together with internal primers designed from the available DsMV sequence near the 3 '-terminus. To obtain the $5^{\prime}$-proximal sequence of the genome, a PCR primer that targeted the first 5'-conserved 20 nt of the DsMV genome (Dash et al. 2013) was coupled with a primer designed from the specific DsMV sequence near the $5^{\prime}$-terminus of the two Hawaii strains obtained from the NGS data obtained in this study.

All PCR products were cloned into the pGEM-T Easy (Promega) vector and at least three clones were submitted to the University of Hawaii's Advanced Studies of Genomics, Proteomics, and Bioinformatics Laboratory for sequencing. The sequences were aligned using VECTOR NTI 10.0 software (Informax, Frederick, MD). To fill gaps in the assembled genomes, clones with the same sequence in the overlapping region as the assembled genome were considered to represent the same strain.

Phylogenetic and recombination analyses. The polyprotein sequences of select potyvirus species and six strains of DsMV, including Hawaii Strains I and II, were subjected to phylogenetic analysis with MEGA 6.0 (Tamura 2013) and the maximum likelihood method with 1,000 bootstrap replicates. Four available complete genomes of DsMV were aligned with Hawaii Strains I and II using VECTOR NTI 10.0 software (Informax) with default parameters, based on the whole genome. To identify any correlation in molecular variation between geographic origin or plant host, we performed a phylogenetic analysis of the $\mathrm{CP}$ amino acid sequences of all 30 available
DsMV isolates using the maximum likelihood method, with Konjac mosaic virus (KMV, LC114492) as the outgroup. To further confirm the genetic relationships of Hawaii Strains I and II with other DsMV isolates, we conducted recombination analysis using the tools RDP, GENECONV, BOOTSCAN, MAXCHI, CHIMAERA, SISCAN, 3SEQ, and LARD implemented in the RDP4 package in the default configuration (Martin et al. 2015). Only recombination events with a $P$ value $<0.05$ for at least five methods of evaluation were regarded as valid (Wu et al. 2015). The GenBank accession numbers of the viruses used in the alignment and in the phylogenetic and recombination analyses are as follows: Zucchini yellow mosaic virus (ZYMV, NC003224); Passion fruit woodiness virus (PWV, NC014790.2); Hardenbergia mosaic virus (HarMV, HQ161080.1); Bean common mosaic virus (BCMV, NC003397); Bean common mosaic necrosis virus (BCMNV, U19287.1); East Asian Passiflora virus (EAPV, NC007728); Wisteria vein mosaic virus (WVMV, NC007216); Watermelon mosaic virus (WMV, KU24008.1); Soybean mosaic virus (SMV, AJ628750.1); Calla lily latent virus (CLLV, EF105299); Peanut mottle virus (PeMoV, NC002600); Maize dwarf mosaic virus (MDMV, AJ001691); Papaya ringspot virus (PRSV, S46722.1); Konjac mosaic virus (KMV, NC007913.1); Potato virus Y (PVY, X12456); Yam mosaic virus (YMV, NC004752); Tobacco etch virus (TEV, M15239); Sweet potato feathery mottle virus (SPFMV, NC001841); Turnip mosaic virus (TuMV, D10927); vanilla mosaic virus (VanMV, KX505964.1, AJ616721.1, AJ616720.1, AJ616719.1); and Dasheen mosaic virus (DsMV: NC003537.1, KJ786965.1, KT026108.1, KY242358, KY242359; AM910407.1, JN692173.1, EF199550.1, U00122.1, AJ298036.1; LC114515, KT372699, AF511485.1, AF048981.1, FJ160764.2, U08124.1, AF169832.1, HQ207542.2, LC114514, AY994104.1, AY994105.2, DQ925466.1, LC114493.2, LC114513, EU420058.1, AJ628756.1).

RT-PCR detection and distribution of DsMV. To determine the distribution of DsMV in Hawaii, we designed a pair of general DsMV detection primers (DMV 5708-5731-F/DMV 6131-6154-R) derived from the conserved sequences of available DsMV strains (Table 1). Specific primers were also designed to detect and distinguish DsMV Hawaii Strain I (DMV 01-20-F/Taro Sample I 227-249-R) and Hawaii Strain II (Taro Sample II-5105-5129 F/Taro Sample II 5630-5654 R) (Table 1) according to specific regions within the genomes of these two strains. The specificity of these primers was verified by matching the sequences of five clones from each strain to the corresponding genome.

Total RNA was extracted using the RNeasy Plant Mini Kit (QIAGEN, Valencia, CA) according to the manufacturer's instructions. Synthesis of cDNA was performed using M-MLV reverse transcription (Promega) according to the manufacturer's directions. The cDNA $(1 \mu \mathrm{l})$ was subjected to PCR in a $20 \mu \mathrm{l}$ reaction mixture containing $10 \mu \mathrm{l} \mathrm{GoTaq}$
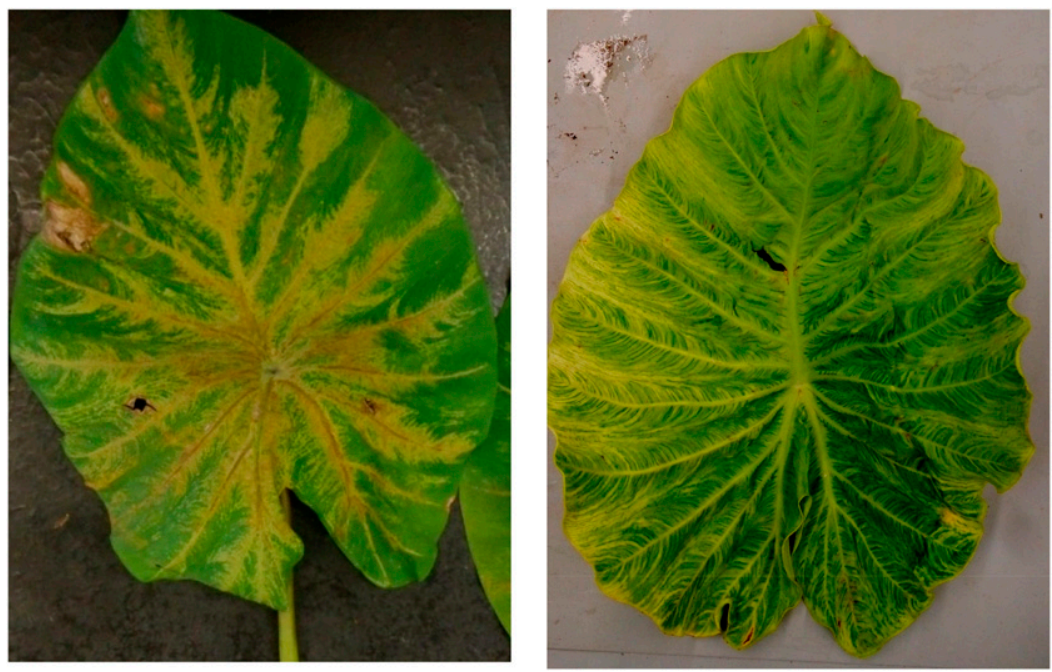

Fig. 1. Taro leaves with typical symptoms of Dasheen mosaic virus collected on the island of Oahu, Hawaii. Left, sample 'Taro l'; right, sample 'Taro II'. 
Master Mix (Promega), and 10 pmol each forward and reverse primers. For general DsMV detection, the thermal cycler program was: $95^{\circ} \mathrm{C}$ for $5 \mathrm{~min}$; followed by 35 cycles of amplification at $95^{\circ} \mathrm{C}$ for $30 \mathrm{~s}, 50^{\circ} \mathrm{C}$ for $30 \mathrm{~s}, 72^{\circ} \mathrm{C}$ for $30 \mathrm{~s}$; and a final extension at $72^{\circ} \mathrm{C}$ for $10 \mathrm{~min}$. To detect Hawaii Strain I, the thermal cycler program was: $95^{\circ} \mathrm{C}$ for $5 \mathrm{~min}$; followed by 40 cycles of amplification at $95^{\circ} \mathrm{C}$ for $30 \mathrm{~s}, 55^{\circ} \mathrm{C}$ for $30 \mathrm{~s}, 72^{\circ} \mathrm{C}$ for $30 \mathrm{~s}$; and a final extension at $72^{\circ} \mathrm{C}$ for $10 \mathrm{~min}$. For Hawaii Strain II, the thermal cycler program was: $95^{\circ} \mathrm{C}$ for $5 \mathrm{~min}$; followed by 35 cycles of amplification at $95^{\circ} \mathrm{C}$ for $60 \mathrm{~s}, 50^{\circ} \mathrm{C}$ for $60 \mathrm{~s}, 72^{\circ} \mathrm{C}$ for $60 \mathrm{~s}$; and a final extension at $72^{\circ} \mathrm{C}$ for $10 \mathrm{~min}$. The amplification products were subsequently analyzed on $1 \%$ agarose gels.

\section{Results}

Identification of two distinct Hawaiian DsMV strains. NGS performed on an Illumina MiSeq platform generated a total of 1,541,254 and 1,003,700 useable reads from Taro Sample I and Taro Sample II, respectively (Table 2). Distinct strains of DsMV were identified in Taro Sample I (Hawaii Strain I) and Taro Sample II (Hawaii Strain II). The nucleic acid sequence of Hawaii Strain I was 10,002 nt in length (GenBank KY242358) and had 5'- and $3^{\prime}$-nontranslated regions (NTRs) of 152 and $274 \mathrm{nt}$, respectively. The sequence of Hawaii Strain II was 10,019 nt in length (KY242359) and had $5^{\prime}$ - and $3^{\prime}$-NTRs of 166 and $280 \mathrm{nt}$, respectively. The 5 '-proximal NTR sequences were obtained from PCR amplifications using a PCR primer that targeted the first 20 nt of the $5^{\prime}$-NTR of the DsMV genome (Dash et al. 2013) coupled with a primer designed from the specific DsMV sequence near the 5'-terminus. Both Hawaii Strains I and II had typical DsMV genome organizations, consisting of a large polyprotein of 3,191 and 3,192 amino acid residues, respectively. We have also identified a badnavirus from the taro samples. Characterization of the taro Badnavirus is in progress.

Sequence alignment and phylogenetic analyses. The genome sequences of DsMV Hawaii Strain I and Hawaii Strain II had identities of 78 to $84 \%$ with the four DsMV isolates available in GenBank (Table 3). For particular coding regions, the nucleotide identity between these six isolates was 65 to $81 \%$ for P1, 79 to $85 \%$ for $\mathrm{HC}$ Pro, 74 to $85 \%$ for P3, 70 to $88 \%$ for $6 \mathrm{~K} 1,81$ to $87 \%$ for CI, 77 to $89 \%$ for $6 \mathrm{~K} 2,81$ to $90 \%$ for NIa-VPg, 77 to $86 \%$ for NIa-Pro, 79 to $86 \%$ for NIb, and 78 to $89 \%$ for the $\mathrm{CP}$. The corresponding amino acid identities in these regions were 64 to $83 \%$ for P1, 92 to $96 \%$ for HC-Pro, 72 to $92 \%$ for P3, 90 to $100 \%$ for $6 \mathrm{~K} 1,94$ to $97 \%$ for CI, 83 to $98 \%$ for $6 \mathrm{~K} 2,91$ to $99 \%$ for NIa-VPg, 88 to $97 \%$ for NIa-Pro, 88 to $95 \%$ for NIb, and 87 to $94 \%$ for the CP. Sequence identities of the $5^{\prime}$ - and $3^{\prime}$-NTRs ranged from 56 to $80 \%$ and 73 to $91 \%$, respectively. Results of the alignment analysis showed that among the six DsMV strains examined, Hawaii Strain I had the highest identity with VanMV (KX505964.1) for all protein regions except 6K1. Hawaii Strain II had the highest identity with the CTCRI-II-14 isolate (KT026108.1) for nearly all protein regions except HC-Pro, CP, and NIa-Vpg (data not shown).

Phylogenetic analysis based on the polyprotein amino acid sequence indicated that all available DsMV isolates formed a single branch that then clustered with 10 other potyviruses to form one subgroup, the BCMV subgroup (Chen et al. 2001). This subgroup included: ZYMV (NC003224), PWV (NC014790.2), HarMV (HQ161080.1), BCMV (NC003397), (BCMNV, U19287.1), EAPV (NC007728), WVMV (NC007216), WMV (KU24008.1), SMV (AJ628750.1), and CLLV (EF105299). PeMoV is separated from the other sequences of BCMV subgroup. Another subgroup includes eight potyviruses: MDMV belongs to the first clade; PRSV belongs to a second clade; KMV belongs to the third clade; and PVY, YMV, TEV, SPFMV, and TuMV clustered a fourth distinct clade (Fig. 2). Hawaii Strain I was most closely related to VanMV (KX505964.1) and these two strains clustered together. Hawaii Strain II was most closely related to CTCRI-II14 (KT026108.1) and these two clustered with DsMV (KJ786965) and DsMV (NC003537.1) (Fig. 2). Phylogenetic analysis using the $\mathrm{CP}$ amino acid sequence of DsMV strains in GenBank showed that

Table 1. Detection primers for Dasheen mosaic virus (DsMV) used in this study

\begin{tabular}{llccc}
\hline Primer ID & \multicolumn{1}{c}{ Sequence $\left(\mathbf{5}^{\prime} \mathbf{-} \mathbf{3}^{\prime}\right)$} & Tm $\left({ }^{\mathbf{O}} \mathbf{C}\right)$ & Product size $(\mathbf{b p})$ & Purpose \\
\hline DMV 5708-5731-F & caggcacatcaattttctaac & 50.5 & $447 \mathrm{bp}$ & Detection of DsMV \\
DMV 6131-6154-R & ggctccacaccataatgtgcacg & 60.7 & & Detection of DsMV Hawaii Strain I \\
DMV 01-20-F & aaattaaaacatctcaacaa & 43.1 & & \\
Taro Sample I 227-249-R & gaatgtaatggcaccagtagtgc & 56.1 & & Detection of DsMV Hawaii Strain II \\
Taro Sample II-5105-5129 F & tttatcgcggtgtactgtaaacag & 55.4 & $550 \mathrm{bp}$ & \\
Taro Sample II 5630-5654 R & caaataccgcttctgatacttcc & 57.4 & & \\
\hline
\end{tabular}

Table 2. Deep sequencing and assembly data for infected samples of Dasheen mosaic virus (DsMV) collected in Hawaii

\begin{tabular}{|c|c|c|c|c|c|c|c|c|c|}
\hline $\begin{array}{l}\text { Sample } \\
\text { ID }\end{array}$ & $\begin{array}{l}\text { No. of } \\
\text { reads }\end{array}$ & $\begin{array}{c}\text { No. of } \\
\text { nonvirus } \\
\text { contigs }\end{array}$ & $\begin{array}{l}\text { No. of } \\
\text { plant } \\
\text { virus } \\
\text { contigs }\end{array}$ & $\begin{array}{l}\text { No. of } \\
\text { DsMV } \\
\text { contigs }\end{array}$ & $\begin{array}{c}\text { Sequence } \\
\text { length of } \\
\text { DsMV contigs }\end{array}$ & $\begin{array}{l}\text { Percentage of } \\
\text { identical } \\
\text { matches }\end{array}$ & $\begin{array}{c}\text { Reads } \\
\text { assembling to } \\
\text { the reference }\end{array}$ & $\begin{array}{c}\text { Coverage } \\
(\%)\end{array}$ & Genome gaps \\
\hline Taro I & $1,541,254$ & 65,536 & 318 & 207 & $202-4,212 \mathrm{nt}$ & 70.62 to $100 \%$ & 186,648 & 94.2 & $\triangle 1-244 ; 8,771-8,800 ; 9,897-3^{\prime}$ end \\
\hline Taro II & $1,003,770$ & 5,072 & 89 & 26 & $229-8,679 \mathrm{nt}$ & 72.57 to $100 \%$ & 242,302 & 96.2 & $\triangle 1-381$ \\
\hline
\end{tabular}

Table 3. Identities (\%) among Hawaii strains of Dasheen mosaic virus and other strains based on the genomic nucleotide sequence

\begin{tabular}{lccccc}
\hline & KY242359 $^{\mathbf{a}}$ & KT026108.1 $^{\mathbf{b}}$ & KJ786965.1 $^{\mathbf{c}}$ & NC003537.1 $^{\mathbf{d}}$ & KX505964.1 $^{\text {e }}$ \\
\hline KY242358 & 78 & 79 & 78 & 79 & 84 \\
KY242359 & & 84 & 82 & 83 & 78 \\
KT026108.1 & & 83 & 85 & 78 \\
KJ786965.1 & & & & 77 \\
NC003537.1 & & & & 78 \\
\hline
\end{tabular}

${ }^{a}$ KY242359: Hawaii Strain II from Colocasia esculenta, U.S.A.

${ }^{\mathrm{b}}$ KT026108.1: CTCRI-II-14 isolate from Colocasia esculenta, India.

${ }^{\mathrm{c}}$ KJ786965.1: T10 isolate from Amorphophallus paeoniifolius, India.

${ }^{\mathrm{d}} \mathrm{NC} \_$003537.1: An isolate from Zantedeschia aethiopica, China.

${ }^{\mathrm{e}}$ KX505964.1: Vanilla mosaic virus from Vanilla tahitensis, Cook Island.

${ }^{\mathrm{f}}$ KY242358: Hawaii Strain I from Colocasia esculenta, U.S.A. 
Hawaii Strains I and II were more closely related to three isolates; two isolates infecting C. esculenta from New Zealand (AY994104.1 and AY994105.2), and one isolate infecting V. tahitensis from French Polynesia (AJ616719.1) (Fig. 3). To reveal the correlation between molecular variation and the geographic origin of the isolates and their host plants, phylogenetic analyses were conducted for isolates originating from the same geographic region (Fig. 4) and from the same host plants (Fig. 5). Analysis of the eight DsMV isolates from mainland China or Taiwan showed that three isolates from Zantedeschia (KT372699, AF511485.1, and NC003537.1) clustered within the same branch, as did the two isolates from Pinellia (EU420058.1 and AJ628756.1). These results revealed similarities in molecular variations among host-plant species. Phylogenetic analysis of nine DsMV isolates from C. esculenta showed that four from the U.S.A. (U00122.1, U08124.1, Hawaii Strains I and II) were situated on different branches. This result revealed no correlation between geographic origin and molecular variation among these isolates.

Recombination analyses. The program RDP4 (Martin et al. 2015) was used to explore possible recombination events in the six available complete genome sequences of DsMV including the new strains Hawaii Strain I and Hawaii Strain II (Table 4 and Fig. 6). The analysis detected three putative recombinants (NC_003537.1 from China, KT026108.1 and KJ786965.1 from India) with a high probability $(P<0.05)$ using seven of the eight statistical methods implemented in RDP4. The results indicate that recombination occurred predominantly in the regions of $\mathrm{P} 1, \mathrm{C} 1$ to NIa-Pro, and NIb to CP that were produced by three recombination events, each of which contained more breakpoints than the other regions (Fig. 6). The blue region and the red regions indicate the recombination hotspots associated with these three recombination events (Fig. 6). The DsMV strain NC003537.1 from China (number 1 in Table 4 and Fig. 6) is a recombinant of KJ786965.1 from India and Hawaii Strain II from the U.S.A. in the region between nucleotides 688 and 924. The other DsMV strains KT026108.1 and KJ786965.1 (numbers 2 and 3 in Table 4 and Fig. 6) are recombinants of Hawaii Strain II from the U.S.A. and NC003537.1 from China within the regions from nucleotides 8,797 to 8,929 and nucleotides 5,058 to 6,713 , respectively. In the three recombinants, Hawaii Strain II was the major parent for NC003537.1

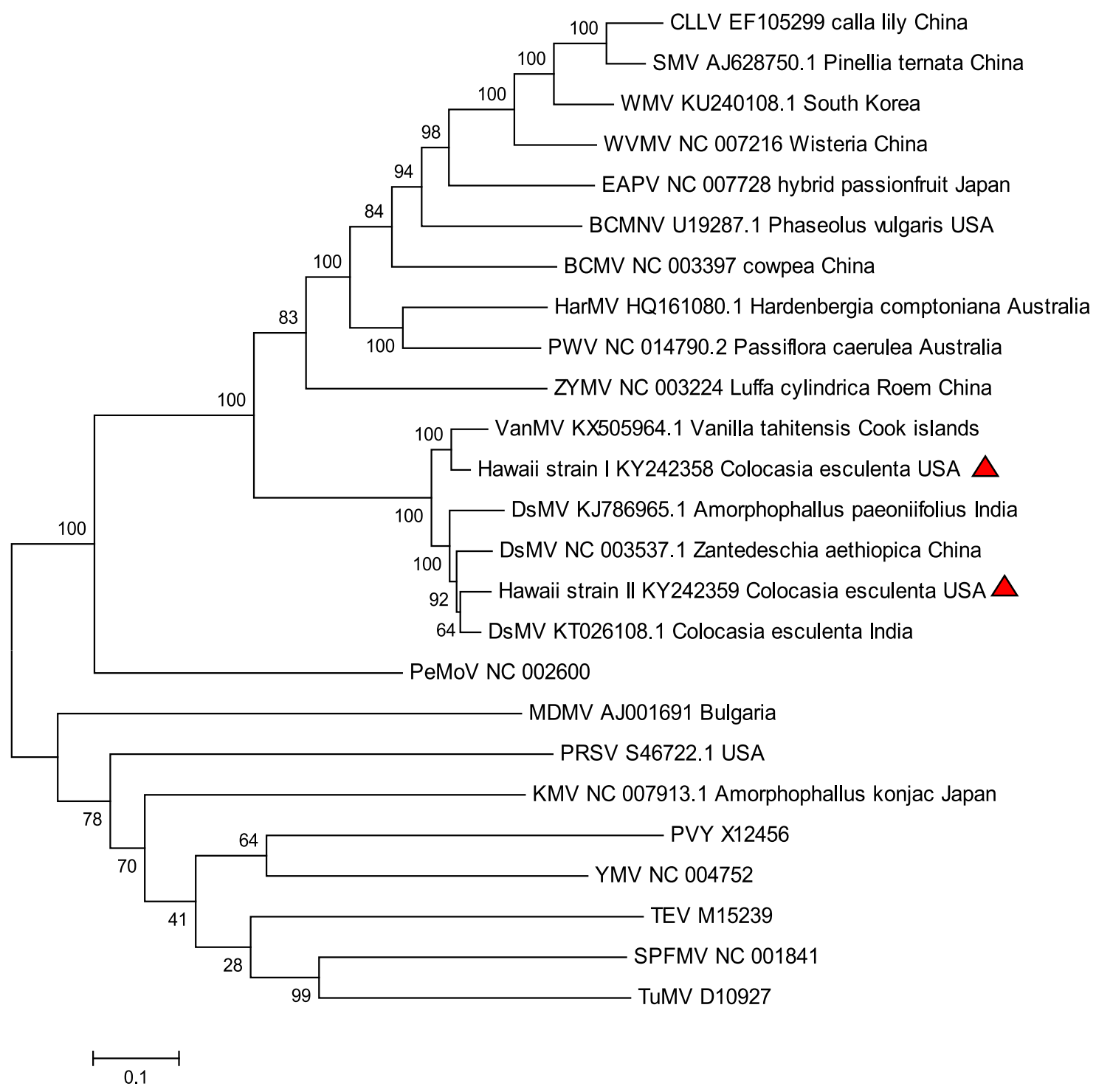

Fig. 2. Maximum likelihood tree showing the relationship of Dasheen mosaic virus (DsMV), Hawaii Strains I and II, with 23 sequenced members of the genus Potyvirus based on the amino acid sequences of their polyproteins. Values at the branch points indicate the percentages of 1,000 bootstrap replicates. For horizontal branch lengths, the scale bar represents a genetic distance of 0.1. The viruses used for alignment were retrieved from GenBank: Calla lily latent virus (CLLV, EF105299), Soybean mosaic virus (SMV, AJ628750.1), Watermelon mosaic virus (WMV, KU240108.1), Wisteria vein mosaic virus (WVMV, NC_007216), East Asian Passiflora virus (EAPV, NC_007728), Bean common mosaic necrosis virus (BCMNV, U19287.1), Bean common mosaic virus (BCMV, NC_003397), Hardenbergia mosaic virus (HarMV, HQ161080.1), Passion fruit woodiness virus (PWV, NC_014790.2), Zucchini yellow mosaic virus (ZYMV, NC_003224), vanilla mosaic virus (VanMV, KX505964.1), DsMV (NC_003537.1, KJ786965.1, KT026108.1, KY242358, KY242359), Peanut mottle virus (PeMoV, NC_002600), Maize dwarf mosaic virus (MDMV, AJ001691), Papaya ringspot virus (PRSV, S46722.1), Konjac mosaic virus (KMV, NC 007913.1), Potato virus Y (PVY, X12456), Yam mosaic virus (YMV, NC 004752), Tobacco etch virus (TEV, M15239), Sweet potato feathery mottle virus (SPFMV, NC_001841), and Turnip mosaic virus (TuMV, D10927). Hawaii Strains I and II of DsMV are indicated with red triangles. 
from China as well as the minor parent of KJ786965.1 and KT026108.1 from India. Similarly, Hawaii Strain II and NC003537.1 were the minor and major parents respectively of two Indian isolates (Table 4). The minor parent is the parent strain contributing the smaller fraction of the sequence; and the major parent is the parent strain contributing the larger fraction of the sequence.
Detection and distribution of DsMV strains in Hawaii. Three pairs of primers (DMV 5708-5731-F/DMV 6131-6154-R; DMV 01-20-F/Taro Sample I 227-249-R; and Taro Sample II-5105-5129 F/Taro Sample II 5630-5654 R) were used to develop PCR detection assays in which amplicons of the expected size were generated. Sequence analysis of five clones from each strain-specific assay confirmed

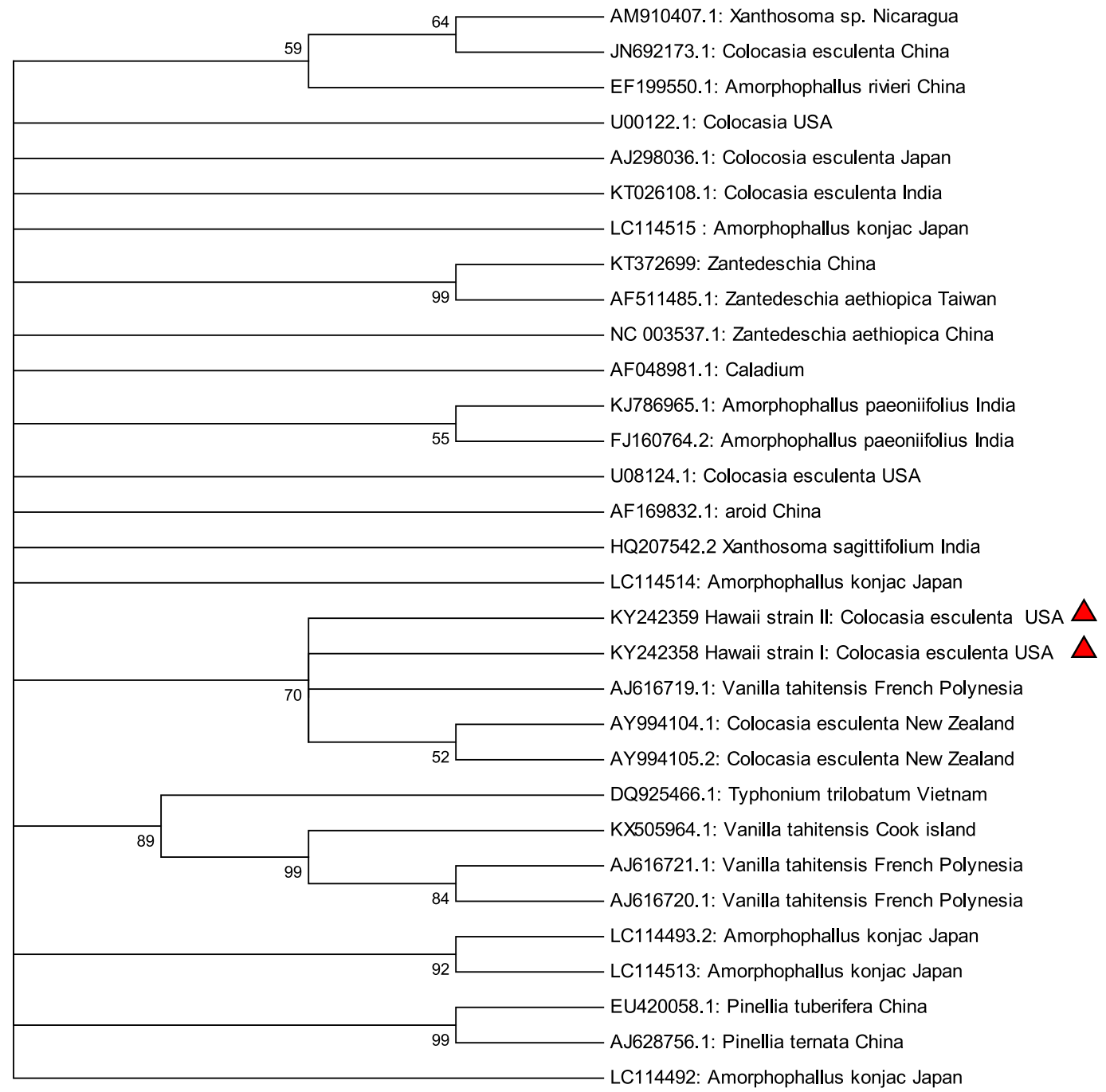

Fig. 3. Maximum likelihood tree showing the relationship of Dasheen mosaic virus (DsMV) Hawaii strains with 30 available isolates of DsMV based on the amino acid sequences of their coat proteins. Values at the branch points indicate the percentages of 1,000 bootstrap replicates. Isolates used for alignment were retrieved from GenBank: vanilla mosaic virus (VanMV: KX505964.1, AJ616721.1, AJ616720.1, AJ616719.1), DsMV (NC_003537.1, KJ786965.1, KT026108.1, KY242358, KY242359, AM910407.1, JN692173.1, EF199550.1, U00122.1, AJ298036.1, LC114515, KT372699, AF511485.1, AF048981.1, FJ160764.2, U08124.1, AF169832.1, HQ207542.2, LC114514, AY994104.1, AY994105.2, DQ925466.1, LC114493.2, LC114513, EU420058.1, AJ628756.1), and Konjac mosaic virus (KMV: LC114492). Hawaii Strains I and II of DsMV are indicated with red triangles.

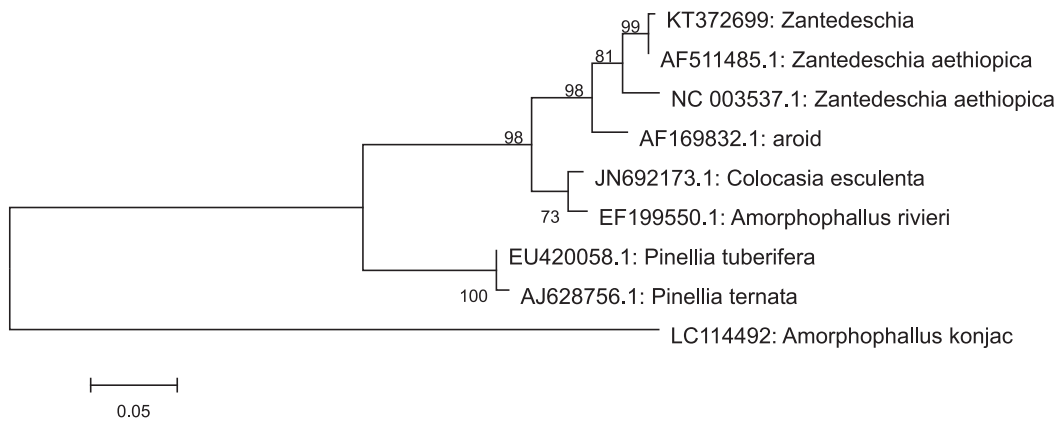

Fig. 4. Maximum likelihood tree showing the relationship of eight available Dasheen mosaic virus (DsMV) isolates from different host plants in mainland China and Taiwan based on the amino acid sequences of their coat proteins. Values at the branch points indicate the percentages of 1,000 bootstrap replicates. The scale bar for the horizontal branch lengths represents a genetic distance of 0.05. Isolates used for alignment were retrieved from GenBank: DsMV (NC003537.1, AF169832.1, JN692173.1, EF199550.1, KT372699, AF511485.1, EU420058.1, AJ628756.1). Konjac mosaic virus (KMV: LC114492) was used as the outgroup. 
the specificity of those primers for Hawaii Strain I and Hawaii Strain II, as all five clones were identical to the corresponding region of the assembled strain genome (data not shown).

The incidence of DsMV among the 328 taro samples collected from Oahu, Hawaii, Maui, Molokai, and Kauai was 40\% (23/58), $20 \%$ (16/79), 25\% (18/71), 29\% (15/52), and 47\% (32/68), respectively. The percentage of samples that tested positive for DsMV on the five islands overall was 32\% (104/328). Hawaii Strain II was found on each of the five islands sampled with average incidence of $11 \%$, while Hawaii Strain I occurred on all islands except Molokai (Table 5) with an overall average incidence of 6\%. On the island of Kauai, five taro samples were infected by both Hawaii Strain I and Hawaii Strain II (data not shown).

We then used Taro Sample I, which was also used for the original NGS, as the template to examine further the mixed infection phenomenon. We sequenced partial regions of the NIb and $\mathrm{CP}$ genes, the most variable region within the DsMV genome, with primer pair DV855978-F/DV9325-43-R. Analysis of the amino acid sequences of five clones revealed the presence of two unique clones ( $\mathrm{C} 1$ and $\mathrm{C} 2$, Fig. 7) in addition to the Hawaii Strain I. In the five clones, there are three of Hawaii Strain I and one each of C1 and C2. Clone 2 has $98 \%$ identity to Hawaii Strain II so it is similar to Hawaii Strain II. However, Clone 1 has $70 \%$ identity to Hawaii Strain II and $89 \%$ identity to Hawaii Strain I. In addition, Clone 1 was about 30 amino acids longer than Hawaii Strain I (Fig. 7). These results showed that a mixture of at least three DsMV strains were present in a single taro sample.

\section{Discussion}

Virus diseases are a major threat to taro production worldwide. To date, seven viruses have been reported from taro: DsMV, Colocasia bobone disease-associated virus $(\mathrm{CBDaV})$, Taro bacilliform virus
(TaBV), Taro vein chlorosis virus (TaVCV), Groundnut bud necrosis virus (GBNV), Cucumber mosaic virus (CMV), and Taro bacilliform $\mathrm{CH}$ virus (TaBCHV) (Brunt et al. 1990; Kazmi et al. 2015; Pearson et al. 1999; Sivaprasad et al. 2011; Wang et al. 2014; Yang et al. 2003a, b). DsMV was first reported on taro by Zettler in 1970 , but to date only four complete genomes are available in GenBank. Conventional Sanger-based sequencing has commonly been used to determine viral genomes, but it cannot provide the comprehensive view of the plant virome now made available with NGS (Deboever et al. 2015; Kreuze et al. 2009; Wu et al. 2010). To detect the presence of plant viral genomes, dsRNA extracted from infected tissue has been used as starting material to construct cDNA libraries (Al Rwahnih et al. 2009; Coetzee et al. 2010). To obtain the fulllength coding sequences of Hawaii Strain I and Hawaii Strain II, we have also started with dsRNAs isolated from infected plants to generate cDNA libraries, followed by NGS and conventional Sanger sequencing.

Alignment of the coding region of the Hawaii strains with the four available DsMV genomes in GenBank indicated that the 6K1 and CI regions were relatively more conserved, and the $\mathrm{P} 1$ region was the most variable. This is in agreement with results for most other potyviruses (Shukla et al. 1994). According to the current ICTV species demarcation criteria for different species within the genus Potyvirus (Adams et al. 2005, 2011), the complete genomic nucleotide sequence identity must be less than $85 \%$, the $\mathrm{CP}$ amino acid sequence identity must be less than $80 \%$, and the 3 -UTR nucleotide sequence identity must be less than $75 \%$. Based on the sequence identities obtained in this study, Hawaii Strain I and Hawaii Strain II are divergent strains of DsMV with identities of 78 to $84 \%, 87$ to $92 \%$, and 74 to $85 \%$ over the complete viral genomes nucleotide, $\mathrm{CP}$ amino acid, and $3^{\prime}$-UTR nucleotide sequences respectively, compared with the

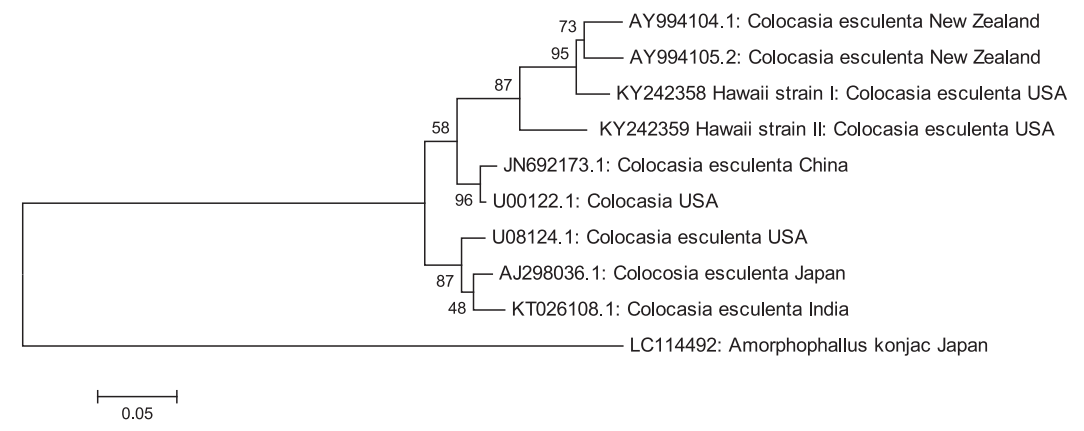

Fig. 5. Maximum likelihood tree showing the relationship of nine available Dasheen mosaic virus (DsMV) isolates from taro (Colocasia esculenta) in different countries based on the amino acid sequences of their coat proteins. Values at the branch points indicate the percentages of 1,000 bootstrap replicates. The scale bar for the horizontal branch lengths represents a genetic distance of 0.05. Isolates used for alignment were retrieved from GenBank: DsMV (KT026108.1, KY242358, KY242359, JN692173.1, U00122.1, AJ298036.1, U08124.1, AY994104.1, AY994105.2). Konjac mosaic virus (KMV: LC114492) was used as the outgroup.

Table 4. Information about recombinants based on the six available complete genome sequences of Dasheen mosaic virus (DsMV) as analyzed by RDP4

\begin{tabular}{|c|c|c|c|c|c|c|c|c|c|c|c|c|}
\hline \multirow{3}{*}{$\begin{array}{l}\text { Recombinant } \\
\text { number }\end{array}$} & \multirow{2}{*}{\multicolumn{2}{|c|}{$\begin{array}{c}\text { Breakpoints } \\
\text { in the } \\
\text { alignment }\end{array}$}} & \multicolumn{3}{|c|}{ Information on recombinants } & & & & & & & \\
\hline & & & \multirow{2}{*}{$\begin{array}{l}\text { Recombinant } \\
\text { sequence(s) }\end{array}$} & \multirow{2}{*}{$\begin{array}{c}\text { Minor } \\
\text { parental } \\
\text { sequence }(\mathbf{s})^{\mathbf{a}}\end{array}$} & \multirow{2}{*}{$\begin{array}{c}\text { Major } \\
\text { parental } \\
\text { sequence }(\mathbf{s})^{\mathbf{b}}\end{array}$} & \multicolumn{7}{|c|}{$P$ value for the seven detection methods in RDP4 } \\
\hline & Begin & End & & & & RDP & GENECONV & Bootscan & Maxchi & Chimaera & SiSscan & LARD \\
\hline 1 & 688 & 924 & $\begin{array}{l}\text { NC003537.1 } \\
\text { China }\end{array}$ & $\begin{array}{l}\text { KJ786965.1 } \\
\text { India }\end{array}$ & $\begin{array}{l}\text { KY242359 } \\
\text { Hawaii-II } \\
\text { U.S.A. }\end{array}$ & $3.52 \mathrm{E}-13$ & $3.69 \mathrm{E}-18$ & 5.34E-10 & $1.08 \mathrm{E}-09$ & $1.26 \mathrm{E}-06$ & $5.85 \mathrm{E}-11$ & $\mathrm{NS}^{\mathrm{c}}$ \\
\hline 2 & 8,797 & 8,929 & $\begin{array}{l}\text { KT026108.1 } \\
\text { India }\end{array}$ & $\begin{array}{c}\text { KY242359 } \\
\text { Hawaii-II } \\
\text { U.S.A. }\end{array}$ & $\begin{array}{l}\text { NC_003537.1 } \\
\text { China }\end{array}$ & $8.56 \mathrm{E}-04$ & NS & $1.91 \mathrm{E}-02$ & $6.33 \mathrm{E}-03$ & $6.82 \mathrm{E}-03$ & $7.24 \mathrm{E}-08$ & NS \\
\hline 3 & 5,058 & 6,713 & $\begin{array}{l}\text { KJ786965.1 } \\
\text { India }\end{array}$ & $\begin{array}{c}\text { KY242359 } \\
\text { Hawaii-II } \\
\text { U.S.A. }\end{array}$ & $\begin{array}{l}\text { NC_003537.1 } \\
\text { China }\end{array}$ & $2.12 \mathrm{E}-03$ & NS & $9.58 \mathrm{E}-03$ & 4.16E-02 & $5.98 \mathrm{E}-03$ & 4.89E-06 & NS \\
\hline
\end{tabular}

\footnotetext{
${ }^{a}$ Minor parent: Parent strain contributing the smaller fraction of the sequence.

b Major parent: Parent strain contributing the larger fraction of the sequence.

${ }^{c}$ NS: No significant $P$ value was recorded for the recombination event using this method.
} 
other four available complete genomes of the virus. Phylogenetic and alignment analyses indicate that Hawaii Strain I and VanMV are the most closely related, sharing $84 \%$ nucleotide identity over their entire genomes. This value was less than $80 \%$ when compared with other DsMV strains. Since vanilla is the only reported host of VanMV, it has previously been unclear whether VanMV is a distinct potyvirus species or a strain of DsMV (Wisler et al. 1987). More recent sequence analyses have confirmed that VanMV is in fact a vanillainfecting strain of DsMV (Farreyrol et al. 2006; Puli'uvea et al. 2016). It is not known if the Hawaii Strain I is able to infect vanilla, but a recent survey for potyviruses in Hawaii's orchid industry did not detect DsMV in vanilla or other orchids (Melzer et al., unpublished data).

Hawaii Strain II is most closely related to DsMV CTCRI-II-14 strain from India. It is not known if the recombination events occurred before or after this strain was introduced by taro trade among nations. Our results contribute added knowledge of the DsMV genome and facilitate the further study of its genetic variation and the development of more accurate diagnostic assays to monitor spread of the virus.

Phylogenetic analysis of the CP region conducted using $30 \mathrm{DsMV}$ sequences indicated the groupings were not correlated with geographic origin. There was, however, some correlation to the host plant. As with the VanMV strains infecting vanilla in the South Pacific islands, the host plant may exert some selection pressure on the strains of DsMV that infect them (Farreyrol et al. 2006).

For single-stranded RNA viruses, recombination is a major evolutionary means of adapting to new hosts and environments (Nagy 2008); recombination has occurred frequently in the evolution of potyviruses (Gagarinova et al. 2008; Ogawa et al. 2008; Revers et al. 1996; Seo et al. 2009). Our results reflect this propensity since the six DsMV strains examined in this study revealed three that are recombinants. This is in agreement with previous studies showing that the $\mathrm{C} 1$ and $\mathrm{CP}$ regions are recombination hotspots in the potyviruses (Bousalem et al. 2000; Cervera et al. 1993; Cuevas et al. 2012; Karasev et al. 2011; Li et al. 2013; Mangrauthia et al. 2008; Ogawa et al. 2012; Tian et al. 2011; Wylie and Jones 2009). These studies indicate the importance of recombination in determining the fitness of potyvirus populations (Balasubramanian and Selvarajan 2014; Sztuba-Solińska et al. 2011). Furthermore, the recombinants were the parents of other recombinants. For example, isolate NC003537.1 from China and isolate KJ786965.1 from India reflect the complex recombination patterns of the DsMV population. The presence of recombinants among isolates from China, the U.S.A., and India may reflect the increasingly frequent economic exchanges among these three countries.

We developed detection assays capable of identifying two strains of DsMV in the same plant tissue. The degenerate generic primers DMV 5708-5731-F and DMV 6131-6154-R were derived from conserved nucleotide sequences and amplified the region of the DsMV genome from the $3^{\prime}$-end of $\mathrm{C} 1$ to the $5^{\prime}$-end of NIa-Vpg. DsMV Hawaii Strains I and II can be detected and distinguished from other isolates in taro tissue using RT-PCR protocols and the specific primers DMV 01-20-F/Taro Sample I 227-249-R and Taro Sample II5105-5129 F/Taro Sample II 5630-5654 R. Other detection assays have been developed to detect DsMV (Babu et al. 2011; Hu et al. 1995; Maino 2003; Matthews et al. 1996). To our knowledge, however, this is the first report of the use of specific primers to differentiate among strains of DsMV occurring in the same plant.

$\mathrm{Hu}$ et al. (1995) investigated the occurrence and distribution of DsMV in Hawaii. Using ELISA, DsMV was detected in nine taro cultivars sampled from 14 commercial fields, with an overall incidence of $63 \%$ (295/465). This is about a two-thirds greater occurrence of DsMV than detected in our study. However, DsMV was detected much more frequently in some cultivars than others, ranging from 16 to $100 \%$ (Hu et al. 1995). Another possible explanation for the lower percentage of infection that we found is that we only sampled fields once during the year whereas $\mathrm{Hu}$ et al. (1995) tested the same samples four times from September 1993 to January 1994 (Hu et al. 1995); it is known that virus titers in taro plants can vary considerably throughout the year (Hu et al. 1995). It is also possible that the RT-PCR assays used in this study to detect and distinguish DsMV are not as robust as the serological assay used by Hu et al. (1995) due to the sequence variation present in DsMV strains.

The RT-PCR assays developed in this study provide an alternative method of detecting and monitoring DsMV Hawaii Strain I and Hawaii Strain II in taro and may also facilitate in controlling this virus disease in the field. These assays have shown that mixed infections of these two strains occur in single taro plants collected from Kauai in this study, with five taro samples apparently infected by both strains. In addition, other isolates or strains were identified from the original Taro Sample I that was used for NGS. The CP region of the new isolate $(\mathrm{C} 1)$ is about 30 amino acids longer than either Hawaii Strain I or

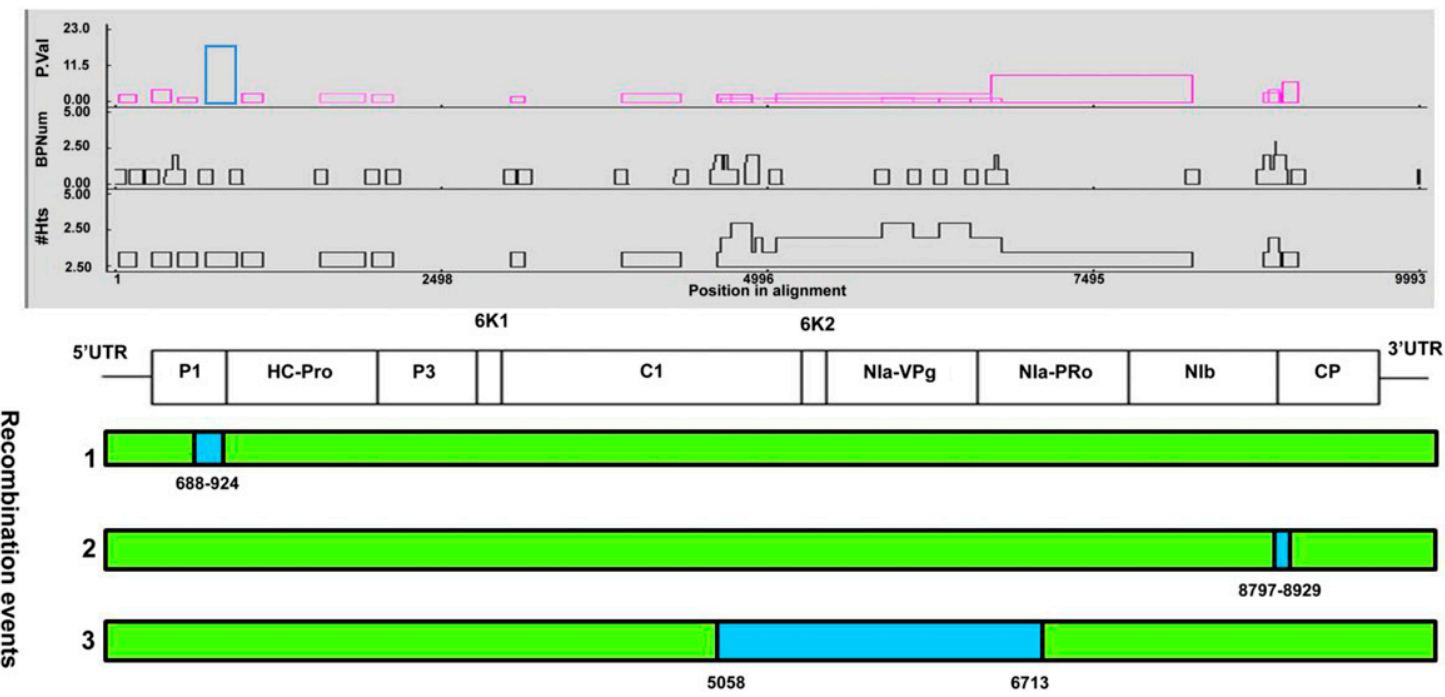

Fig. 6. Recombination events detected in the six available isolates of Dasheen mosaic virus (DsMV) based on their genome sequences using the RDP4 program. The analysis revealed three recombination events. Top panel: Distribution of recombination hotspot sites in the DsMV genome sequences. P-Val: the minimum probability values associated with detected events; BP Num: Breakpoint number; \#Hits: the number of events detected in particular regions of the alignment. Middle panel: Genomic organization of DsMV where genes of the polyprotein are displayed. Bottom panel: Patterns of recombinants (shaded rectangles) in DsMV populations. The recombinants 1,2 , and 3 correspond with those in Table 4. The accession numbers of DsMV used in the recombination analysis are as follows: KT026108.1 (Colocasia esculenta, India), NC003537.1 (Zantedeschia aethiopica, China), KJ786965.1 (Amorphophallus paeoniifolius, India), vanilla mosaic virus, KX505964.1 (Vanilla tahitensis, Cook Islands), KY242358 (Colocasia esculenta, Hawaii, U.S.A.), KY242359 (Colocasia esculenta, Hawaii, U.S.A.). Recombination sites were identified by the alignment of genomic sequences using the RDP4 program. 
Hawaii Strain II. It has been reported that variations in CP size apparently reflect genomic diversities among DsMV isolates ( $\mathrm{Li}$ et al. 1999). Therefore, the presence of at least three isolates of DsMV in the Taro Sample I confirms the conclusions of Kamala et al. (2015), who found that there were variants within and between samples, supporting the idea of mixed infections of different DsMV isolates in a single sample. In this study, some of the taro samples found to be infected by DsMV using the degenerate generic PCR primers did not contain either Hawaii Strain I or Hawaii Strain II, suggesting that there are additional unknown diverse DsMV isolates in taro plants in Hawaii.

We selected two taro samples that showed severe symptoms (Fig. 1) for NGS analyses in this study. Our findings of the presence of two distinct strains of DsMV in individual taro plants growing in the same

Table 5. Occurrence and distribution of Hawaii Strain I and Hawaii Strain II of Dasheen mosaic virus (DsMV) on taro in Hawaii

\begin{tabular}{|c|c|c|c|c|}
\hline Islands & Location & Incidence of DsMV ${ }^{a}$ & Incidence of Hawaii Strain $\mathbf{I}^{\mathbf{a}}$ & Incidence of Hawaii Strain $\mathrm{II}^{\mathrm{a}}$ \\
\hline \multirow[t]{8}{*}{ Oahu } & TO1 & $(0 / 2) 0.0 \%$ & $(0 / 2) 0.0 \%$ & $(0 / 2) 0.0 \%$ \\
\hline & $\mathrm{TO} 2$ & (3/12) $25.0 \%$ & (0/12) $0.0 \%$ & (0/12) $0.0 \%$ \\
\hline & TO3 & (10/16) $62.5 \%$ & $(3 / 16) 18.8 \%$ & $(1 / 16) 6.3 \%$ \\
\hline & TO4 & $(0 / 5) 0.0 \%$ & $(0 / 0) 0.0 \%$ & $(0 / 0) 0.0 \%$ \\
\hline & TO5 & (0/1) $0.0 \%$ & (0/1) $0.0 \%$ & (0/1) $0.0 \%$ \\
\hline & TO6 & (3/9) $33.3 \%$ & (1/9) $11.1 \%$ & (0/9) $0.0 \%$ \\
\hline & TO7 & (3/6) $50.0 \%$ & (1/6) $16.7 \%$ & (1/6) $16.7 \%$ \\
\hline & TO8 & (4/7) $57.1 \%$ & (1/7) $14.3 \%$ & (0/7) $0.0 \%$ \\
\hline Oahu total & & (23/58) $39.7 \%$ & $(6 / 58) 10.3 \%$ & (2/58) $3.4 \%$ \\
\hline \multirow[t]{9}{*}{ Hawaii } & TH1 & (2/17) $11.8 \%$ & (0/17) $0.0 \%$ & (1/17) $5.9 \%$ \\
\hline & TH2 & (0/6) $0.0 \%$ & $(0 / 6) 0.0 \%$ & $(0 / 6) 0.0 \%$ \\
\hline & TH3 & $(0 / 2) 0.0 \%$ & $(0 / 2) 0.0 \%$ & $(0 / 2) 0.0 \%$ \\
\hline & TH4 & (2/7) $28.6 \%$ & (1/7) $14.3 \%$ & $(0 / 7) 0.0 \%$ \\
\hline & TH5 & (0/5) $0.0 \%$ & (0/5) $0.0 \%$ & $(0 / 5) 0.0 \%$ \\
\hline & TH6 & $(8 / 12) 66.7 \%$ & $(2 / 12) 16.7 \%$ & (1/12) $8.3 \%$ \\
\hline & TH7 & (0/3) $0.0 \%$ & (0/3) $0.0 \%$ & $(0 / 3) 0.0 \%$ \\
\hline & TH8 & (0/4) $0.0 \%$ & (0/4) $0.0 \%$ & (0/4) $0.0 \%$ \\
\hline & TH9 & $(4 / 23) 17.4 \%$ & (1/23) $4.3 \%$ & (1/23) $4.3 \%$ \\
\hline Hawaii total & & (16/79) $20.3 \%$ & (4/79) $5.1 \%$ & (3/79) $3.8 \%$ \\
\hline \multirow[t]{7}{*}{ Maui } & TM1 & (0/3) $0.0 \%$ & (0/3) $0.0 \%$ & (0/3) $0.0 \%$ \\
\hline & TM2 & (0/2) $0.0 \%$ & (0/2) $0.0 \%$ & $(0 / 2) 0.0 \%$ \\
\hline & TM3 & (0/5) $0.0 \%$ & (0/5) $0.0 \%$ & (0/5) $0.0 \%$ \\
\hline & TM4 & (1/13) $7.7 \%$ & (0/13) $0.0 \%$ & (1/13) $7.7 \%$ \\
\hline & TM5 & (7/14) $50.0 \%$ & (2/14) $14.3 \%$ & (0/14) $0.0 \%$ \\
\hline & TM6 & (1/11) $9.1 \%$ & (0/11) $0.0 \%$ & (0/11) $0.0 \%$ \\
\hline & TM7 & $(9 / 23) 39.1 \%$ & (0/23) $0.0 \%$ & (0/23) $0.0 \%$ \\
\hline Maui total & & (18/71) $25.4 \%$ & (2/71) $2.8 \%$ & (1/71) $1.4 \%$ \\
\hline \multirow[t]{3}{*}{ Molokai } & TMo1 & (12/28) $42.9 \%$ & (0/28) $0.0 \%$ & (7/28) $25.0 \%$ \\
\hline & TMo2 & (0/13) $0.0 \%$ & (0/13) $0.0 \%$ & $(0 / 13) 0.0 \%$ \\
\hline & TMo3 & (3/11) $27.3 \%$ & (0/11) $0.0 \%$ & (1/11) $9.1 \%$ \\
\hline Molokai total & & $(15 / 52) 28.8 \%$ & (0/52) $0.0 \%$ & (8/52) $15.4 \%$ \\
\hline \multirow[t]{8}{*}{ Kauai } & TK1 & (3/8) $37.5 \%$ & (1/8) $12.5 \%$ & (3/8) $37.5 \%$ \\
\hline & TK2 & $(6 / 14) 42.9 \%$ & (1/14) $7.1 \%$ & (3/14) $21.4 \%$ \\
\hline & TK3 & $(5 / 8) 62.5 \%$ & $(0 / 8) 0.0 \%$ & $(5 / 8) 62.5 \%$ \\
\hline & TK4 & (0/3) $0.0 \%$ & (0/3) $0.0 \%$ & (0/3) $0.0 \%$ \\
\hline & TK5 & (0/2) $0.0 \%$ & $(0 / 2) 0.0 \%$ & $(0 / 2) 0.0 \%$ \\
\hline & TK6 & (0/2) $0.0 \%$ & (0/2) $0.0 \%$ & (0/2) $0.0 \%$ \\
\hline & TK7 & (3/8) $37.5 \%$ & (0/8) $0.0 \%$ & (1/8) $12.5 \%$ \\
\hline & TK8 & $(15 / 23) 65.2 \%$ & (4/23) $17.4 \%$ & (9/23) $39.1 \%$ \\
\hline Kauai total ${ }^{\mathrm{b}}$ & & $(32 / 68) 47.1 \%$ & $(6 / 68) 8.8 \%$ & (21/68) 30.9\% \\
\hline Total & 35 & (104/328 $31.7 \%$ & (18/328) $5.5 \%$ & (35/328) $10.7 \%$ \\
\hline
\end{tabular}

a (Number of DsMV positive samples/Number of samples tested).

${ }^{\mathrm{b}}$ Five samples from Kauai tested positive for both Hawaii Strain I and Hawaii Strain II.

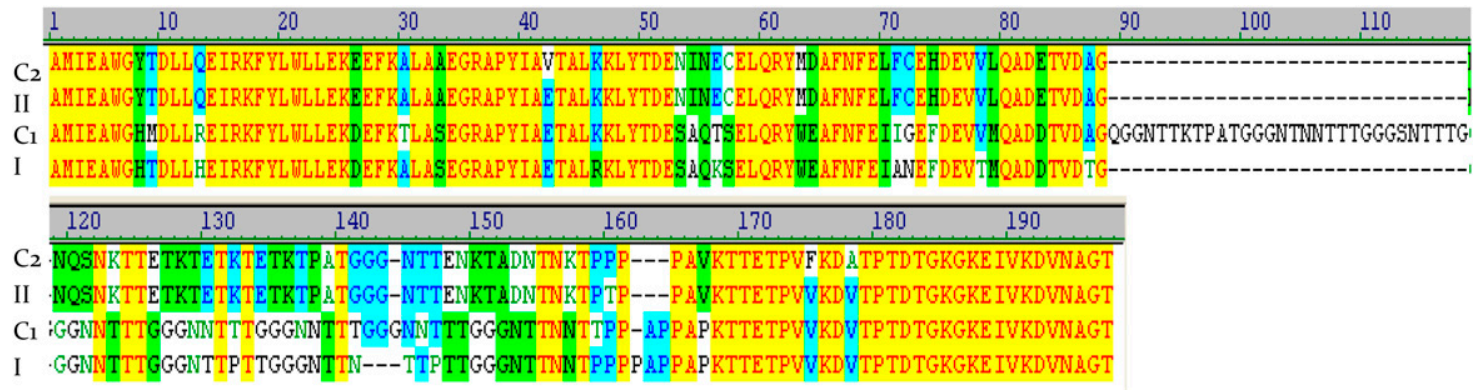

Fig. 7. Sequence comparison of two clones (C1 and C2) from the DsMV-infected Taro Sample I to Hawaii Strains I and II of DsMV. Taro Sample I originally used for NGS was also used as a template in PCR amplification using the degenerate generic primer pair DV8559-78-F/DV9325-43-R. Five positive clones were selected for sequence analyses. Two different isolates (C1 and C2) were found in this Taro Sample I field isolate, in addition to the Hawaii Strain I. 
location, together with the data from the survey study, suggest significant genetic diversity exists in Hawaii's DsMV population. We will screen other aroids in Hawaii for presence of DsMV in the future because other aroid hosts may contribute to the molecular diversity of DsMV. The more in depth understanding of DsMV molecular diversity and distribution in Hawaii will help the management of this important taro disease in Hawaii. The sequencing of additional DsMV strains, along with studies to associate various symptoms with virus populations will be valuable areas for future research.

\section{Acknowledgments}

We thank Dr. Fred Brooks for his critical reviews of this manuscript. The research was supported in part by the USDA National Institute of Food and Agriculture, Hatch HAW09025-H (1001478), and the USDA Agricultural Research Service (58-5320-4-012). Financial support was also provided by research funds from China National Nature Science Foundation (31201487), China Agriculture Research System (Cars-28), Hebei Natural Science Foundation of Higher Education Institutions for Youth (YQ2014023) and the support plan for youth talent in Hebei province.

\section{Literature Cited}

Adams, M. J., Antoniw, J. F., and Fauquet, C. M. 2005. Molecular criteria for genus and species discrimination within the family Potyviridae. Arch. Virol. 150:459-479.

Adams, M. J., Zerbini, M., French, R. C., Rabenstein, F., Stenger, D. C., and Valkonen, J. 2011. Family Potyviridae. Pages 1069-1089 in: The International Committee on the Taxonomy of Viruses, 9th Report. A. M. Q. King, M. J. Adams, E. B. Carstens, and E. J. Lefkowitz, eds. Elsevier/Academic Press, London.

Al Rwahnih, M., Daubert, S., Golino, D., and Rowhani, A. 2009. Deep sequencing analysis of RNAs from a grapevine showing Syrah decline symptoms reveals a multiple virus infection that includes a novel virus. Virology 387:395-401.

Babu, B., Hegde, V., Makeshkumar, T., and Jeeva, M. L. 2011. Detection and identification of Dasheen mosaic virus infecting Colocasia esculenta in India. Indian J. Virol. 22:59-62.

Balasubramanian, V., and Selvarajan, R. 2014. Genetic diversity and recombination analysis in the coat protein gene of Banana bract mosaic virus. Virus Genes 48: 509-517.

Bousalem, M., Dallot, S., and Guyader, S. 2000. Using phylogenetic data to develop molecular tools for the detection and genotyping of Yam mosaic virus. Potential application in molecular epidemiology. J. Virol. Methods 90:25-36.

Brunt, A. A., Crabtree, K., and Gibbs, A. J. 1990. Pages 242-243 in: Viruses of Tropical Plants. CABI, Wallingford, U.K.

Cervera, M. T., Riechmann, J. L., Martin, M. T., and Garcia, J. A. 1993. 3'terminal sequence of the plum pox virus PS and o6 isolates: Evidence for RNA recombination within the potyvirus group. J. Gen. Virol. 74:329-334

Chen, J., Chen, J., Chen, J., and Adams, M. J. 2001. Molecular characterization of an isolate of Dasheen mosaic virus from Zantedeschia aethiopica in China and comparisons in the genus Potyvirus. Arch. Virol. 146:1821-1829.

Coetzee, B., Freeborough, M. J., Maree, H. J., Celton, J. M., Jasper, D., Rees, G., and Burger, J. T. 2010. Deep sequencing analysis of viruses infecting grapevines: virome of a vineyard. Virology 400:157-163.

Cuevas, J. M., Delaunay, A., Visser, J. C., Bellstedt, D.U., Jacquot, E., and Elena, S. F. 2012. Phylogeography and molecular evolution of Potato virus Y. PLoS ONE 7:e37853.

Dash, P. K., Sharma, S., Soni, M., Agarwal, A., Parida, M., and Lakshmana Rao, P. V. 2013. Complete genome sequencing and evolutionary analysis of Indian isolates of Dengue virus type 2. Biochem. Biophys. Res. Commun. 436: 478-485.

Deboever, C., Ghia, E. M., Shepard, P. J., Rassenti, L., Barrett, C. L., Jepsen, K., Jamieson, C. H. M., Carson, D., Kipps, T. J., Frazer, K.A. 2015. Transcriptome sequencing reveals potential mechanism of cryptic $3^{\prime}$ splice site selection in SF3B1-mutated cancers. PLoS Comput. Biol. 11:e1004105.

Farreyrol, K., Pearson, M. N., Grisoni, M., Cohen, D., and Beck, D. 2006. Vanilla mosaic virus isolates from French Polynesia and the Cook Islands are Dasheen mosaic virus strains that exclusively infect vanilla. Arch. Virol. 151:905-919.

Gagarinova, A., Babu, M., Stromvik, M., and Wang, A. 2008. Recombination analysis of Soybean mosaic virus sequences reveals evidence of RNA recombination between distinct pathotypes. Virol. J. 5:143.

Ha, C., Revill, P., Harding, R. M., Vu, M., and Dale, J. L. 2008. Identification and sequence analysis of potyviruses infecting crops in Vietnam. Arch. Virol. 153: $45-60$

Hu, J. S., Meleisea, S., Wang, M., Shaarawy, M. A., and Zettler, F. W. 1995. Dasheen mosaic potyvirus in Hawaiian taro. Australas. Plant Pathol. 24:112-117.

Kamala, S., Makeshkumar, T., Sreekumar, J., and Chakrabarti, S. K. 2015. Whole transcriptome sequencing of diseased elephant foot yam reveals complete genome sequence of Dasheen mosaic virus. Virol. Rep. 5:1-9.

Karasev, A. V., Hu, X., Brown, C. J., Kerlan, C., Nikolaeva, O. V., Crosslin, J. M., and Gray, S. M. 2011. Genetic diversity of the ordinary strain of Potato virus Y (PVY) and origin of recombinant PVY strains. Phytopathology 101:778-785.
Kazmi, S. A., Yang, Z., Hong, N., Wang, G., and Wang, Y. 2015. Characterization by small RNA sequencing of Taro bacilliform $\mathrm{CH}$ Virus (TaBCHV), a novel Badnavirus. PLoS One 10:e134147.

Kreuze, J. F., Perez, A., Untiveros, M., Quispe, D., Fuentes, S., Barker, I., and Simon, R. 2009. Complete viral genome sequence and discovery of novel viruses by deep sequencing of small RNAs: a generic method for diagnosis, discovery and sequencing of viruses. Virology 388:1-7.

Li, R. H., Zettler, F. W., Hiebert, E., and Purcifull, D. E. 1994. Nucleotide sequence and expression of the coat protein $(\mathrm{CP})$ gene of a Dasheen mosaic virus isolate (DsMV-Ch) from Caladium. Phytopathology 84:1105.

Li, R. H., Zettler, F. W., Hiebert, E., Purcifull, D. E., and Morales, F. J. 1999. Differentiation of Dasheen mosaic potyvirus isolates based on variability in the apparent size of the capsid protein in western blots. J. Phytopathol. 147:359-364

Li, R. H., Zettler, F. W., Purcifull, D. E., and Hiebert, E. 1998. The nucleotide sequence of the 3 -terminal region of Dasheen mosaic virus (Caladium isolate) and expression of its coat protein in Escherichia coli for antiserum production. Arch. Virol. 143:2461-2469.

Li, Y., Liu, R., Zhou, T., and Fan, Z. 2013. Genetic diversity and population structure of Sugarcane mosaic virus. Virus Res. 171:242-246.

Lima, J. A. A., and Nascimento, A. K. Q. 2015. New polymerase chain reaction approach for identification of Dasheen mosaic virus in Anthurium andraeanum and other RNA plant viruses. Acta Hortic. 1072:157-164.

Maino, M. K. 2003. The development of a serological-based diagnostic test for Dasheen mosaic potyvirus (DsMV). Master dissertation. Queensland University of Technology, Brisbane, Queensland, Australia.

Mangrauthia, S. K., Parameswari, B., Jain, R. K., and Praveen, S. 2008. Role of genetic recombination in the molecular architecture of Papaya ringspot virus. Biochem. Genet. 46:835-846.

Martin, D. P., Murrell, B., Golden, M., Khoosal, A., and Muhire, B. 2015. RDP4: Detection and analysis of recombination patterns in virus genomes. Virus Evol. 1:vev003.

Matthews, C. G., Milne, K. S., Forster, R. L. S., and Neilson, H. F. 1996 Comparison of four potyvirus isolates infecting aroid species. Acta Hortic. 432:354-363.

Morris, T. J., and Dodds, J. A. 1979. Isolation and analysis of double-stranded RNA from virus-infected plant and fungal tissue. Phytopathology 69:854-858.

Nagy, P. D. 2008. Recombination in plant RNA viruses. Pages 133-156 in: Roossinck (MJ) Plant virus evolution. Springer, Berlin.

Ogawa, T., Nakagawa, A., Hataya, T., and Ohshima, K. 2012. The genetic structure of populations of Potato virus Y in Japan; based on the analysis of 20 full genomic sequences. J. Phytopathol. 160:661-673.

Ogawa, T., Tomitaka, Y., Nakagawa, A., and Ohshima, K. 2008. Genetic structure of a population of Potato virus $\mathrm{Y}$ inducing potato tuber necrotic ringspot disease in Japan; comparison with North American and European populations. Virus Res. 131:199-212.

Pappu, S. S., Pappu, H. R., Lastra, R., and Niblett, C. L. 1994a. Variability in the length of the amino terminal sequence contributes to the coat protein diversity among Dasheen mosaic potyvirus isolates. Arch. Virol. 136:407-413.

Pappu, S. S., Pappu, H. R., Rybicki, E. P., and Niblett, C. L. 1994b. Unusual amino-terminal sequence repeat characterizes the capsid protein of Dasheen mosaic potyvirus. J. Gen. Virol. 75:239-242

Pearson, M. N., Jackson, G. V. H., Saelea, J., and Morar, S. G. 1999. Evidence for two rhabdoviruses in taro (Colocasia esculenta) in the Pacific region. Australas. Plant Pathol. 28:248-253.

Puli'uvea, C., Khan, S., Chang, W. L., Valmonte, G., Pearson, M. N., and Higgins, C. M. 2016. First complete genome sequence of vanilla mosaic strain of Dasheen mosaic virus isolated from the Cook Islands. Arch. Virol. 162:591-595.

Ram, R., Joshi, A., Verma, N., Kulshrestha, S., Raikhy, G., Hallan, V., and Zaidi, A. A. 2003. First report of Dasheen mosaic virus infecting four ornamental aroids in India. Plant Pathol. 52:411.

Revers, F., Le, G. O., Candresse, T., Le Romancer, M., and Dunez, J. 1996. Frequent occurrence of recombinant potyvirus isolates. J. Gen. Virol. 77:1953-1965.

Revill, P. A., Jackson, G. V. H., Hafner, G. J., Yang, I., Maino, M. K., Dowling, M. L., Devitt, L. C., Dale, J. L., and Harding, R. M. 2005. Incidence and distribution of viruses of Taro (Colocasia esculenta) in Pacific Island countries. Australas. Plant Pathol. 34:327-331.

Reyes, G., Ronnberg-Wastljung, A. C., and Nyman, M. 2006. Comparison of field performance between Dasheen mosaic virus-free and virus-infected in vitro plants of Cocoyam (Xanthosoma spp.) in Nicaragua. Exp. Agric. 42:301-310.

Reyes Castro, G., Nyman, M., and Ronnberg-Wastljung, A. C. 2005. Agronomic performance of three cocoyam (Xanthosoma violaceum Schott) genotypes grown in Nicaragua. Euphytica 142:265-272.

Seo, J., Ohshima, K., Lee, H., Son, M., Choi, H., Lee, S. H., Sohn, S. H., and Kim, K. H. 2009. Molecular variability and genetic structure of the population of Soybean mosaic virus based on the analysis of complete genome sequences. Virology 393:91-103.

Shi, Y. H., Hong, X. Y., Chen, J., Adams, M. J., Zheng, H. Y., Lin, L., Qin, B. X. and Chen, J. P. 2005. Further molecular characterisation of potyviruses infecting aroid plants for medicinal use in China. Arch. Virol. 150:125-135.

Shukla, D. D., Ward, C. W., and Brunt, A. A. 1994. Page 516 in: The Potyviridae. CAB International, Wallingford, U.K.

Sivaprasad, Y., Bhaskara Reddy, B. V., Naresh Kumar, C. V. M., Raja Reddy, K. and Sai Gopal, D. V. R. 2011. First report of Groundnut bud necrosis virus infecting taro (Colocasia esculenta). Australas. Plant Dis. Notes 6:30-32. 
Sztuba-Solińska, J., Urbanowicz, A., Figlerowicz, M., and Bujarski, J. J. 2011. RNA-RNA Recombination in plant virus replication and evolution. Annu. Rev. Phytopathol. 49:415-443.

Tamura, K. 2013. MEGA6: Molecular evolutionary genetics analysis version 6.0. Mol. Biol. Evol. 30:2725-2729.

Tian, Y. P., Liu, J. L., Zhang, C. L., Liu, Y. Y., Wang, B., Li, X. D., Guo, Z. K., and Valkonen, J. P. T. 2011. Genetic Diversity of Potato virus Y infecting tobacco crops in China. Phytopathology 101:377-387.

Wang, Y. F., Wang, G. P., Wang, L. P., and Hong, N. 2014. First Report of Cucumber mosaic virus in taro plants in China. Plant Dis. 98:574.

Wisler, G. C., Zettler, F. W., and Mu, L. 1987. Virus infections of vanilla and other orchids in French Polynesia. Plant Dis. 71:1125-1129.

Wu, B. L., Shang, X. N., Schubert, J., Habekuß, A., Elena, S. F., and Wang, X. F. 2015. Global-scale computational analysis of genomic sequences reveals the recombination pattern and coevolution dynamics of cereal-infecting geminiviruses. Sci. Rep. 5:8153.

Wu, Q., Luo, Y., Lu, R., Lau, N., Lai, E. C., Li, W. X., and Ding, S. W. 2010. Virus discovery by deep sequencing and assembly of virus-derived small silencing RNAs. Proc. Natl. Acad. Sci. USA 107:1606-1611.
Wylie, S. J., and Jones, R. A. C. 2009. Role of recombination in the evolution of host specialization within Bean yellow mosaic virus. Phyopathology 99: 512-518.

Yang, I. C., Hafner, G. J., Dale, J. L., and Harding, R. M. 2003a. Genomic characterisation of Taro bacilliform virus. Arch. Virol. 148:937-949.

Yang, I. C., Hafner, G. J., Revill, P. A., Dale, J. L., and Harding, R. M. 2003b. Sequence diversity of South Pacific isolates of Taro bacilliform virus and the development of a PCR-based diagnostic test. Arch. Virol. 148: 1957-1968.

Yu, X., Sheng, J. J., Zheng, X. W., Diao, Y., Zheng, X. F., Xie, K. Q., Zhou, M. Q., and $\mathrm{Hu}, \mathrm{Z}$. L. 2015. First report of Dasheen mosaic virus infecting lotus (Nelumbo nucifera) in China. Plant Dis. 99:1449.

Zettler, F. W., Foxe, M. J., Hartman, R. D., Edwardson, J. R., and Christie, R. G. 1970. Filamentous viruses infecting dasheen and other araceous plants. Phytopathology 60:983-987.

Zhang, J., Borth, W. B., Lin, B., Dey Kishore, K., Melzer, M. J., Shen, H., Pu, X., Sun, D., and Hu, J. S. 2016. Deep sequencing of banana bract mosaic virus from flowering ginger (Alpinia purpurata) and development of an immunocapture RT-LAMP detection assay. Arch. Virol. 161:1783-1795. 